\title{
Estudi de reaccions àcid-base amb ajuda de les eines del laboratori virtual de química
}

\author{
José Ángel Hernández Santadaría \\ Institut Badalona VII
}

L'article proposa diverses activitats que utilitzen les eines del laboratori virtual de The ChemCollective per treballar de manera pràctica amb l'alumnat alguns dels continguts més rellevants relacionats amb les reaccions àcid-base del currículum de química de batxillerat.

Paraules clau: reaccions àcid-base, laboratori virtual, simulació, química de batxillerat

\section{El laboratori virtual de The ChemCollective}

El laboratori virtual de The ChemCollective (fig. 1) és un entorn de simulació que representa un laboratori de química centrat principalment en dissolucions aquoses. És gratuït i es pot usar en línia (1). També podem descarregar el programa, instal-lar-lo en el nostre ordinador i utilitzar-lo sense connexió (2). S'ha traduït a diversos idiomes, entre ells el català (3).

L'objectiu d'aquest article no és presentar les grans possibilitats didàctiques dels laboratoris virtuals i en particular del laboratori virtual desenvolupat per The ChemCollective. Tampoc pretén explicar de manera detallada com s'utilitza aquesta potent eina. Considerem més pràctic suggerir al professorat interessat que accedeixi a l'aplicació i que

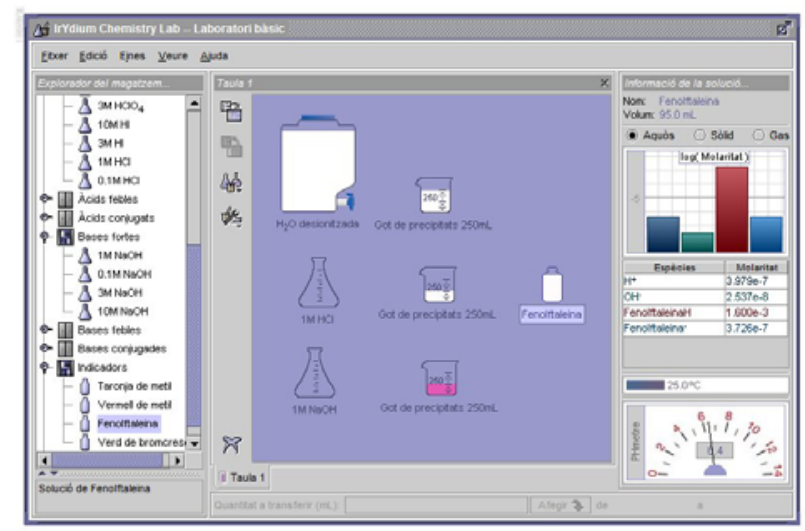

Figura 1. Interfície del laboratori virtual de The ChemCollective. dediqui uns minuts a explorar-la. Descobrirà que la seva utilització és molt senzilla i intuïtiva i en poc temps començarà a habituar-se a treballar amb la seva interfície.

Per completar la informació sobre el funcionament i les possibilitats didàctiques d'aquest laboratori virtual recomanem la lectura de l'article publicat per Jordi Cuadros de l'Institut Químic de Sarrià a la revista Educació Química - EduQ (4)

\section{Continguts i experiments relacionats amb els equilibris àcid-base}

En el currículum de la matèria de química de batxillerat (5) es relacionen els diferents continguts, contextos i treballs pràctics corresponents a l'equilibri àcid-base.

Pel que fa als treballs experimentals, el currículum de la matèria estableix els següents:

\section{Primer de batxillerat}

- Caracterització i determinació experimental dels àcids i les bases

- Determinació experimental de la quantitat d'un àcid o una base que conté un producte quotidià

\section{Segon de batxillerat}

- Investigació de la variació del pH en diluir un àcid fort i un àcid feble

- Observació del canvi de color de diferents indicadors àcid-base 
- Obtenció i interpretació de la corba de valoració d'un àcid fort o una base forta

- Observació de la capacitat reguladora del pH de certes solucions. Investigació experimental de la capacitat reguladora del $\mathrm{pH}$ de l'aigua mineral carbònica.

Al seminari de física i química de l'institut BadaIona VII hem optat per realitzar a primer curs de batxillerat la determinació experimental de la quantitat d'àcid acètic present en un vinagre comercial per ajudar així l'alumnat a familiaritzar-se amb els materials i la tècnica de la volumetria àcid-base.

A segon es programen dos treballs pràctics sobre el tema: l'estudi del comportament de les dissolucions tampó davant l'addició de petites quantitats d'àcids i bases forts, utilitzant sensors de $\mathrm{pH}$ i el programari Multilab (6 ) i l'obtenció i estudi de corbes de valoració àcid-base aprofitant les possibilitats d'alguns applets Java disponibles a Internet (7).

Per altra banda, l'autor ha dissenyat activitats que permeten simular, utilitzant les eines del laboratori virtual, dos dels treballs pràctics plantejats en el currículum de química de batxillerat ("Investigació de la variació del $\mathrm{pH}$ en diluir un àcid fort $\mathrm{i}$ un àcid feble" i "Observació del canvi de color de diferents indicadors àcid-base").

Els guions d'activitats que es presenten a continuació també permeten treballar altres continguts relacionats amb les reaccions àcid-base d'una manera pràctica i atractiva per a l'alumnat.

\section{Proposta d'activitats}

Per realitzar les activitats proposades cal disposar d'un ordinador amb connexió a Internet i accedir a la versió en línia i en català del ChemCollective's Virtual Chemistry Lab (3).

S'han elaborat dos guions: un que inclou un conjunt d'activitats dirigides a l'alumnat de primer curs de batxillerat i l'altre amb activitats que formen part del currículum de segon curs.

Guió 1 (activitats dirigides a l'alumnat de primer de batxillerat):

- El pH dels àcids forts i dels àcids febles

- El pH de les bases fortes i de les bases febles

- Observació del canvi de colors de diferents indicadors

- Reacció de neutralització
Guió 2 (activitats dirigides a l'alumnat de segon de batxillerat):

- Equilibri iònic de l' $\mathrm{H}_{2} \mathrm{O}$

- Investigació de la variació del pH en diluir un àcid fort i un àcid feble

- Hidròlisi de les sals

- Dissolucions reguladores del pH

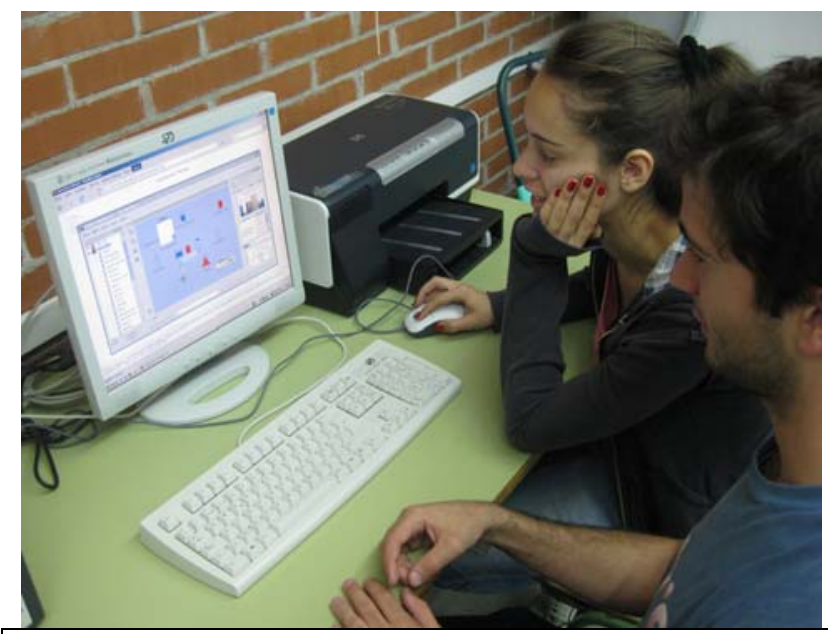

Figura 2. Alumnes de batxillerat utilitzant el laboratori virtual per realitzar les activitats proposades.

Els guions de les activitats tenen una estructura semblant a la dels tradicionals guions de pràctiques de laboratori, amb petites adaptacions que tenen en compte que s'està treballant en un entorn virtual:

- Objectius de l'activitat

- Fonament teòric

- Materials i productes del laboratori virtual

- Procediment i recollida de dades

- Anàlisi dels resultats i conclusions

Aquests guions estan a disposició de tot el professorat que els vulgui utilitzar. Es poden descarregar des del curs de Moodle "Aula virtual de química de batxillerat" (8) dins de les activitats del tema "Reaccions àcid-base", o bé des del suplement.

\section{Investigació de la variació del pH en diluir un àcid fort $i$ un àcid feble}

A mode d'exemple comentarem en detall una de les activitats proposades, la investigació de la variació del pH en diluir un àcid fort i un àcid feble. 
Després d'establir l'objectiu de l'activitat (utilitzant les eines del laboratori virtual de química, investigar la variació del $\mathrm{pH}$ produïda en diluir un àcid fort $i$ un àcid feble) es recorden els conceptes teòrics bàsics (dissociació total dels àcids forts i dissociació parcial dels àcids febles).

A continuació s'indiquen el materials i els productes que cal seleccionar i situar sobre l'espai de treball del laboratori virtual (fig. 3):

- Materials: vasos de precipitats o matrassos erlenmeyer de $250 \mathrm{~mL}$

- Productes: dissolució d'àcid clorhídric $(\mathrm{HCl} 1,0$ $\mathrm{M})$, dissolució d'àcid etanoic $\left(\mathrm{CH}_{3} \mathrm{COOH} 1,0 \mathrm{M}\right)$ i aigua desionitzada

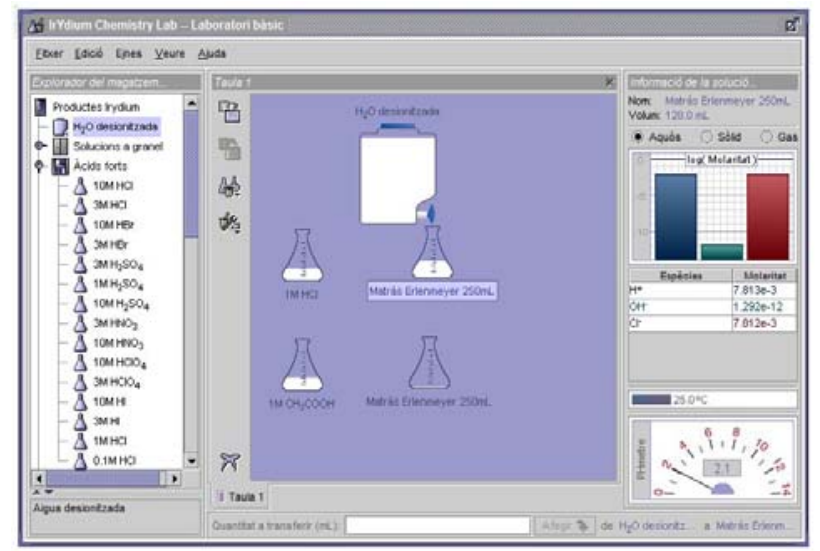

Figura 3. Materials i productes del laboratori virtual utilitzats en la investigació de la variació del pH en diluir un àcid fort i un àcid feble. parts.

El procediment a seguir es divideix en dues

\begin{tabular}{|c|c|c|c|c|c|}
\hline $\begin{array}{c}\text { Volum } \\
\mathbf{H C l} \mathbf{1}, \mathbf{M} \mathbf{M} \\
(\mathbf{m L})\end{array}$ & $\begin{array}{c}\text { Volum } \mathrm{H}_{2} \mathrm{O} \\
\text { afegit } \\
(\mathbf{m L})\end{array}$ & $\begin{array}{c}\text { Volum } \mathrm{H}_{2} \mathrm{O} \\
\text { acumulat } \\
(\mathbf{m L})\end{array}$ & $\begin{array}{c}\text { Volum total } \\
\text { dissolució } \\
(\mathbf{m L})\end{array}$ & $\begin{array}{c}{[\mathrm{HCl}]} \\
\left(\mathbf{m o l} \cdot \mathbf{L}^{-1}\right)\end{array}$ & $\mathbf{p H}$ \\
\hline 1 & 0 & 0 & 1 & $\mathbf{1 , 0}$ & 0,0 \\
\hline 1 & 1 & 1 & 2 & $\mathbf{0 , 5}$ & 0,3 \\
\hline 1 & 2 & 3 & 4 & $\mathbf{0 , 2 5}$ & 0,6 \\
\hline 1 & 4 & 7 & 8 & $\mathbf{0 , 1 2 5}$ & 0,9 \\
\hline 1 & 8 & 15 & 16 & $\mathbf{0 , 0 6 2}$ & 1,2 \\
\hline 1 & 16 & 31 & 32 & $\mathbf{0 , 0 3 1}$ & 1,5 \\
\hline 1 & 32 & 63 & 64 & $\mathbf{0 , 0 1 6}$ & 1,8 \\
\hline 1 & 64 & 127 & 128 & $\mathbf{0 , 0 0 8}$ & $\mathbf{2 , 1}$ \\
\hline
\end{tabular}

Figura 4. Valors de $\mathrm{pH}$ obtinguts fent dilucions succesives d'una dissolució d'àcid fort

En primer lloc s'estudia la variació del pH en diluir un àcid fort. Es donen indicacions als alumnes perquè agafin un determinat volum de dissolució d'àcid fort (1 $\mathrm{mL}$ d'HCl 1,0 M) i vagin afegint-hi quantitats creixents d'aigua desionitzada per obtenir així dissolucions cada vegada més diluïdes. En cada assaig s'hi afegeix un volum d'aigua doble que en l'assaig anterior i així es va rebaixant la concentració d'àcid a la meitat. La concentració de les diferents dissolucions obtingudes i els valors de $\mathrm{pH}$ mesurats es van recollint en una taula (figura 4).

En segon lloc s'estudia la variació del $\mathrm{pH}$ en diluir un àcid feble. S'agafa un volum determinat d'una dissolució d'àcid feble (1 $\mathrm{mL}$ d'àcid etanoic $1,0 \mathrm{M})$ i es procedeix de la mateixa manera que en el cas de la dilució de l'acid fort, anotant els valors de concentració i pH en una altra taula (figura 5).

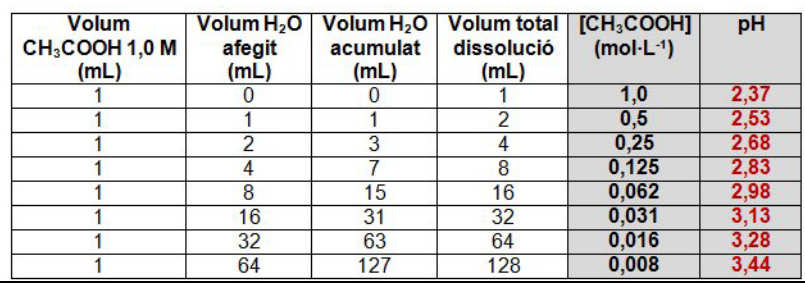

Figura 5. Valors de $\mathrm{pH}$ obtinguts fent dilucions successives d'una dissolució d'àcid feble.

Amb les dades de les dues taules anteriors l'alumnat ha de representar una gràfica que mostri l'evolució del $\mathrm{pH}$ dels dos àcids a mida que en va disminuint la concentració. A l'eix vertical han d'escriure els valors de $\mathrm{pH}$ i a l'eix horitzontal els valors de les concentracions dels àcids, representant les dues sèries de valors sobre els mateixos eixos. Es proposa realitzar la gràfica amb ajuda de l'Excel o d'un programa semblant. El resultat obtingut és el que mostra la figura 6.

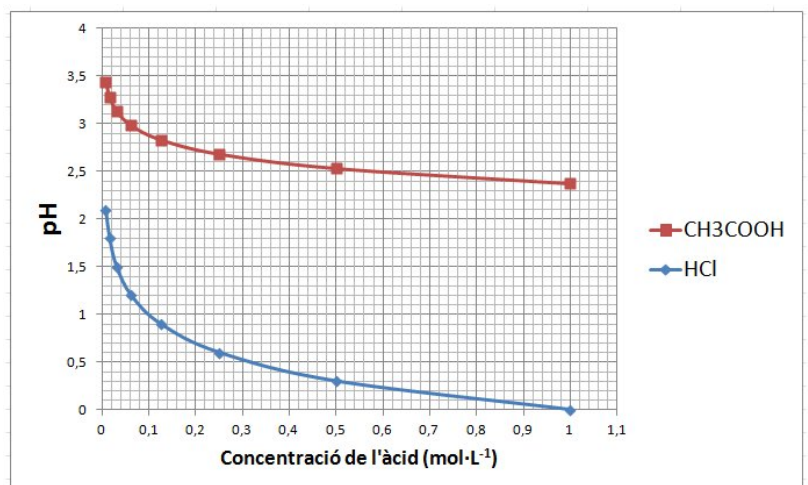

Figura 6. Variació del pH en diluir un àcid fort i un àcid feble

Finalment es demana a l'alumnat que analitzi les gràfiques obtingudes i redacti les seves conclusions. 


\section{Valoracions finals}

Durant el curs 2011-2012, l'autor ha proposat als seus alumnes de primer i segon de batxillerat la realització de les activitats contingudes en els guions que es presenten en aquest article i els resultats han estat molt satisfactoris.

En només uns segons els estudiants es connecten al web del projecte The ChemCollective i l'a-plicació es carrega als ordinadors. Després d'unes senzilles indicacions per part del professor, en pocs minuts l'alumnat aprèn el maneig de les eines bàsiques del laboratori virtual i es pot posar a treballar seguint el guió facilitat. Una vegada que es posen en marxa les activitats, el professor queda alliberat per poder atendre de manera individualitzada els alumnes, ajudant-los a resoldre els dubtes que puguin anar sorgint.

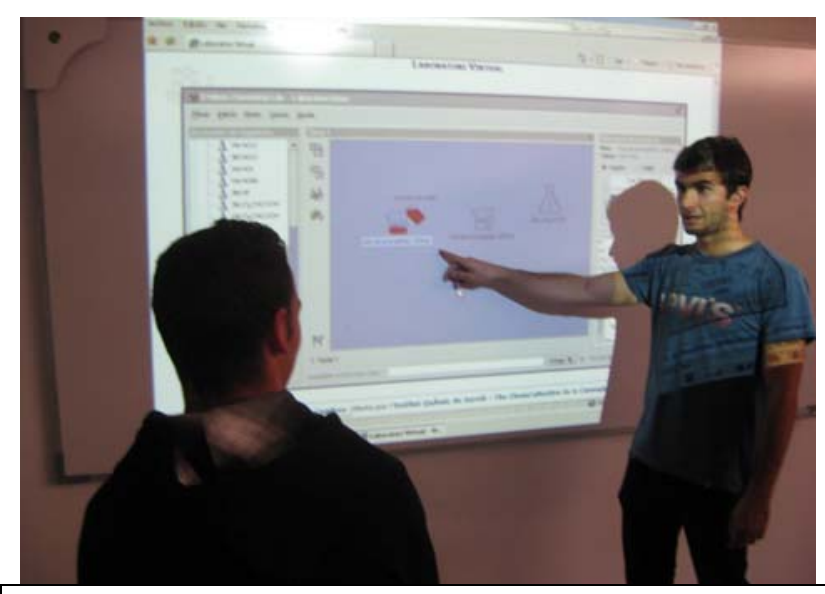

Figura 7. La pissarra digital de l'aula resulta de gran utilitat per introduir l'alumnat en l'ús de les eines del laboratori virtual.

El fet de disposar d'aquests guions ha contribuït a orientar la feina dels alumnes i a treure molt més profit de les sessions de classe. Els guions de les experiències fixen amb claredat els objectius de cada activitat, fan un recordatori dels conceptes teòrics bàsics, indiquen els materials i reactius del la- boratori virtual que s'han de seleccionar, proporcionen els passos del procediment a seguir i faciliten la recollida de les dades que es generen. El qüestionari proposat al final de cada activitat promou l'anàlisi dels resultats i, si s'escau, l'establiment de conclusions.

\section{Referències}

(1) Laboratori virtual The ChemCollective (en línia): http://www.chemcollective.org/applets/vlab.php

(2) Descàrrega del laboratori virtual: http://www.chemcollective.org/iqs/index_ca.htm

(3) Versió en català del laboratori virtual: http://www.chemcollective.org/iqs/vlab/vlabCA.ht $\mathrm{m}$

(4) CUADROS MARGARIT, Jordi (2010) . "Portant el laboratori virtual a l'aula de química: alguns coms i alguns perquès". Educació Química EduQ no 6 , pàgs. 4-12.

(5) Currículum de batxillerat. Decret 142/2008 de 29 de juliol (DOGC núm. 5183)

(6) TORTOSA MORENO, Montserrat (2005). "Què vol dir solució tampó?". Ciències no 4 , pàgs. 1822.

(7) HERNÁNDEZ SANTADARÍA, José Á. (2011) "Utilització d'applets en l'obtenció i estudi de les corbes de valoració àcid-base" . Ciències n 15 , pàgs. 13-18.

(8) Descàrrega dels arxius amb els guions de les activitats (Aula virtual de química): http://agora.xtec.cat/iesb7/moodle/course/view.p hp?id=141

La data de l'última revisió de tots els enllaços és l'1 de juliol de 2012. 